\title{
The Third French Alzheimer Plan: analysis of the influence of a national public health initiative on scientific research productivity and impact
}

\author{
Nicole Haeffner-Cavaillon ${ }^{1 *}$, Patrick Devos ${ }^{2}$, Sylvie Ledoux ${ }^{3}$ and Joël Ménard ${ }^{4,5}$
}

\begin{abstract}
Introduction: The Third National Alzheimer Plan (2008-2012) was a major public health initiative in France that included $€ 200$ million of funding for research in Alzheimer disease and related disorders (AD). The aim of this study was to document trends in French academic output in $A D$ following the implementation of the plan.

Methods: Academic output (i.e., number of original articles) and scientific impact (i.e., article citations) of French research in $\mathrm{AD}$ were obtained from the Web of Knowledge core collection database. Analyses compared the 5-year period immediately before (2004-2008) and after (2009-2013) initiation of the plan. Comparisons were made with stroke, Parkinson disease, AIDS, and diabetes in the 14 leading countries worldwide and regionally within France.

Results: Worldwide production of original scientific articles between the periods 2004-2008 and 2009-2013 increased by $39 \%$, and that for AD increased by $46 \%$. China showed the largest increase and Japan the smallest. The absolute increase in French output on AD (54.6\%) was larger than that for stroke, Parkinson disease, AIDS, or diabetes. Globally, France had the third largest relative increase in output in AD (1.7-fold), behind only India (2.5-fold) and China (1.9-fold). There was a relative 2.3-fold increase in the proportion of French $A D$ articles in the top $1 \%$ globally most cited, larger than that for French articles on stroke, Parkinson disease, AIDS, or diabetes. At the national level, university hospitals participated in nearly $50 \%$ of French AD publications. Analyses by geographical area demonstrated marked heterogeneity. We observed a strong correlation between level of funding and volume of output $\left(R^{2}=0.70\right)$, but not between funding and article impact (proportion of top $10 \%$ globally cited articles; correlation $R^{2}=0.03$ ).

Conclusions: Our study provides evidence of a specific positive impact of the funding provided by the Third National Alzheimer Plan in nearly doubling the global academic scientific output and increasing by 2.3 -fold the top $1 \%$ globally cited articles of France in $\mathrm{AD}$ research. Our bibliometric analyses provide objective and transparent information for policy makers on the relationship between research funding and academic output.
\end{abstract}

\section{Introduction}

A national public health plan is a politically driven choice aimed at the mobilization of financial and human resources to reduce the burden of selected diseases. Since 2001, France, along with several other countries, has successively implemented three national plans against Alzheimer disease and related disorders (AD). The most recent and comprehensive was the Third National Alzheimer Plan, driven directly by the presidency

\footnotetext{
* Correspondence: nicole.haeffner@inserm.fr

'INSERM, Department of Scientific Evaluation, Bibliometric Unit, 101 Rue

Tolbiac, F-75014 Paris, France

Full list of author information is available at the end of the article
}

of the French Republic from 2008 to 2013, in which research was included for the first time as one of the three major objectives of the plan: "to understand, to cure, to care" [1]. Funding for AD was shared between research (€200 million), medical care ( $€ 200$ million), and medicosocial support ( $€ 1.2$ billion). The research funding was allocated by three major bodies: the National Agency for Research (ANR; under the Ministry of Higher Education and Research), the Hospital Program for Clinical Research (PHRC; under the Ministry of Social Affairs and Health), and the Alzheimer Plan Foundation (created to implement the overall initiative). Whereas university hospitals (CHUs) preferentially benefit from PHRC funds, universities in 
partnership with national public research organizations (RPOs; e.g., Institut National de la Santé et de la Recherche Médicale (INSERM), Centre National de la Recherche Scientifique (CNRS), Commissariat à l'Energie Atomique (CEA), and higher education institutions) received funding mainly through ANR applications. Both research organizations were eligible for funding from the Alzheimer Plan Foundation.

Given the level of commitment required for a 5-year national public health plan, it is important to quantify for the scientists, sponsors, and contributors, in a transparent fashion, the scientific impact of the investment made. It is also necessary to review the appropriateness of resource allocation and to provide an objective basis for designing further research strategies at a regional and national level. With these objectives, we performed a bibliometric analysis assessing in parallel the impact of the Third National Alzheimer Plan on both French academic scientific output and the attribution of research funding [2], comparing the 5-year period immediately before the plan (2004-2008) with the 5 years after initiation of the plan (2009-2013). The relative contribution of France to the global literature on $\mathrm{AD}$ was assessed in terms of both the quantity (i.e., number of articles) and quality (i.e., representation in the top $1 \%$ and top $10 \%$ of globally cited publications) relative to four other major disease areas (stroke, Parkinson disease, HIV, and diabetes) and benchmarked by international comparisons.

\section{Methods}

\section{The Alzheimer Plan Foundation}

A non-profit private foundation was created in June 2008 by the French Ministry of High Education and Research to coordinate and implement the research measures of the Third National Alzheimer Plan. The Foundation connects multiple governmental funding sources, such as the ANR and the PHRC, to support research projects on basic, clinical, or social research and also plays the part of a think tank to encourage public and private financial support. Five major pharmaceutical companies operating in France (AstraZeneca, Merck Sharp \& Dohme, Servier, Sanofi, and Ipsen) provided some financial support as a permanent guarantee. These private founders were members of the board of directors but had no input on the scientific options.

\section{Bibliometric analyses}

To evaluate the international and national impact of the Third French Alzheimer Plan, bibliometric analyses were performed in July 2014 to examine the production of original scientific articles from France in comparison with other countries and diseases other than AD. The analyses compared the 5-year period immediately before the plan (2004-2008) with the 5 years after initiation of the plan (2009-2013) and were conducted using the Thomson Reuters Web of Knowledge core collection database. All analyses included only full articles in peer- reviewed journals; other forms of publication were excluded (i.e., proceedings papers, reviews, abstracts, obituaries, corrections, editorials).

\section{Research output}

Research output was defined as the number of articles published in journals covered by the Science Citation Index, the Social Science Citation Index, and the Arts and Humanities Citation Index in the Web of Science core collection database.

\section{Comparisons with other countries and major disease areas}

Research output was evaluated in AD and related neurodegenerative dementias in comparison with four other major comparator disease areas (stroke, Parkinson disease, HIV, and diabetes) by use of appropriate search terms in the topic search. The search included the title, abstract, keywords, and Thomson Reuters Keywords Plus fields. $\mathrm{AD}$ and related neurodegenerative dementia terms searchers were "Alzheimer" or "fronto-temporal dementia" or "semantic dementia" or "posterior cortical atrophy " or "progressive aphasia" or "Body Lewy Body disease" or "beta amyloid" or "amyloid precursor" or "APP and processing" or "presenilin" or "tau protein." Articles related to CADASIL, Parkinson, Creutzfeldt-Jakob, prion, a myotrophic Lateral Sclerosis, Huntington, multiple sclerosis, Niemann-Pick, Down syndrome, or Wilson disease were discarded because they were not supported by the Third National Alzheimer Plan. As Thomson Reuters KeyWords Plus consist of words and phrases harvested from the titles of the cited articles and are embedded in the topic search, we excluded articles containing the following terms: "epilepsy" or "autism" or "schizophrenia" or "bipolar glioma" or "carcinoma" or "stroke" or "cancer" or "child" or "fetal" or "infant" or "newborn" or "preterm" or "pediatric" or "prenatal" or "neonatal" or "infant" or "adolescent" or "stroke" or "trauma."

HIV terms searched were "acquired immune deficiency syndrome" or "HIV." Diabetes terms searched were "diabetes" or "diabetic." The stroke term searched was "stroke." For international and national comparative assessments, country and city information was obtained from the author field. Each publication was counted in full for every institution or country identified in the author affiliations; that is, our assumption was that each author, institution, and country in the listed affiliations made a non-negligible contribution.

\section{Top $1 \%$ and top $10 \%$ publications}

Globally highly cited publications were identified using Thomson Reuters Essential Science Indicators (ESI) thresholds, which select the top $1 \%$ or top $10 \%$ of articles by total citations in each annual cohort from each of the 22 ESI domains. Each article is assign to 1 of the 
22 scientific domains (and only 1) based on the journal in which it appears. These indicators allow one to identify the "essential core" of journal articles within a research field. The title, abstract, and summary of each article were manually screened for the top $1 \%$ globally cited articles for comparison of the top six European Union (EU) countries and the top $10 \%$ globally cited articles for comparison of geographical areas in France.

\section{Output increase}

Output increase represents the absolute percentage increase in the output of publications by a given entity (i.e., a country or French region) between the periods 2004-2008 and 2009-2013.

\section{Output relative increase}

Output relative increase represents the percentage increase in the output of publications by a given entity (i.e., a country or French region) between the periods 2004-2008 and 2009-2013, divided by the overall percentage increase of the world (for analyses by country) or France (for analyses by French region) between those periods.

\section{Relative citation impact}

The citation count for each publication attributed to a field was divided by the mean citations for that field in the year of publication.

\section{SIGAPS score}

The SIGAPS system has been used in France since 2006 to assess the research contribution of all CHUs. It relies on a classification of the publications into five classes (A-E) based on the journal impact factor distribution in each research topic's category as defined by the Journal Citation Report Science Edition (JCR 2013 edition). For each article, the SIGAPS score (from 1 to 32 ) is calculated based on the class of the journal in which the article was published and the position in the author list of the author affiliated with the CHU. When several researchers of one $\mathrm{CHU}$ coauthor the same article, it is counted once for the institution with the highest score [3].

\section{Research field assessment}

The research fields of articles comprised clinical investigation (including clinic cohorts), biology (including clinical chemistry, experimental models, biochemistry, experimental and cellular pharmacology), neuroimaging, epidemiology (population cohorts), genetics, and neuropathology. Research fields were allocated based on the journal (using the Thomson Reuters ESI domains), the article title, the content of the abstract, and the specialization of the main authors.

\section{Geographical research areas in France}

Twenty-nine geographical research areas were defined by a specific query using the corresponding French cities hosting universities and CHUs. The city-based queries included the suburb cities where affiliated hospitals, universities, and RPOs are located; for example, the Lyon research area included Lyon, Pierre-Bénite, Bron, and Villeurbanne. Analysis focused on the scientific performance of the major French research areas, including publications from RPOs, higher education institutes, universities, and $\mathrm{CHUs}$ with at least 50 articles dedicated to AD between 2004 and 2013. CHU output was obtained from the SIGAPS system referencing over 70,000 authors belonging to the $29 \mathrm{CHUs}$. For Paris, the research area was divided into the 13 Paris universities; for example, Paris 11 included Orsay, Gif-sur-Yvette, Saclay, Cachan, Châtenay-Malabry, Bures-sur-Yvettes, Villejuif, and Bicêtre. As CHUs of Paris are affiliated with Assistance Publique-Hôpitaux de Paris, hospital affiliations were corrected manually. Each hospital article was attributed to its university; for example, publications from Hôpital Pitié-Salpêtrière, Hôpital Charles-Foix, Hôpital Saint-Antoine, Hôpital Tenon, Hôpital Rothschild, and Hôpital Trousseau-La Roche-Guyon were attributed to the Paris 06 research area. For high-impact articles (top $10 \%)$, the bibliometric outputs for the French geographical research areas were also screened manually by author affiliation. In some specific cases, top $10 \%$ articles were attributed to specific regional research areas only if one author was in a leading position (i.e., corresponding author). Each top $10 \%$ article was attributed to only one research area.

\section{Results}

\section{Allocation of funding in the Third French Alzheimer Plan,} 2008-2012

The Third French Alzheimer Plan included a total of $€ 200$ million dedicated to research, of which $€ 45$ million were already engaged through RPOs, €5-7 million for doctoral positions and staff positions through universities, $€ 1$ million (0.5 \%) for the Alzheimer Plan Foundation management and $€ 126$ million distributed through grant applications. The Ministry of Health supported 50 clinical research projects through PHRCs ( $€ 24.7$ million), $€ 34.1$ million was provided through the ANR, and $€ 41.9$ million was distributed through the Alzheimer Plan Foundation (Additional file 1: Figure S1a).

Grant applications for specific research projects were reviewed by committees of independent, largely nonFrench experts. The quality of the grant applications assessed by experts was the primary criterion for selection. There was minimal consideration given to allocation to specific fields of research, and no geographic targeting. Similar levels of funding support were allocated to clinical 
investigation (36.5 \% of research funds) and to fundamental research $(24.3 \%$ for biology and $8.2 \%$ for genetics). Almost $20 \%$ of the funds were dedicated to imaging and technology and more than $10 \%$ to social sciences and epidemiological studies (Additional file 1: Figure S1b).

\section{Regional funding and scientific output in Alzheimer disease in France}

The impact of the Third French Alzheimer Plan on scientific output was assessed for the major French research areas $(n=29)$, including publications from universities, RPOs, higher education institutes, and CHUs. Production was assessed in terms of both volume (number of articles) and impact (proportion of papers in the top $10 \%$ globally cited and the SIGAPS score for CHUs). For the period 2004-2008, five geographical research areas produced at least 100 articles related to AD (Paris 06, Toulouse, Paris 11, Lille, and Bordeaux). During the period 2009-2013, output increased in all geographical research areas and 9 produced at least 100 articles related to AD (Paris 06, Toulouse, Bordeaux, Montpellier, Paris 11, Lille, Paris 05, Lyon, and Marseille).

The global quantitative increase in scientific output in $\mathrm{AD}(+69.6 \%)$ also appeared to yield an increase in impact, as measured by the number of French articles in the top $10 \%$ globally cited: For $57.5 \%$ of the top $10 \%$ cited articles, a French author has a leading position. We observed an increase of $134 \%$ (from 189 to 442) in the number of top $10 \%$ articles between the periods 20042008 and 2009-2013. In 2004-2008, 5 research areas led (corresponding author) more than ten top $10 \%$ articles, whereas in 2009-2013 a total of 13 research areas led more than ten top $10 \%$ articles (Table 1). It is noteworthy that the percentage of top $10 \%$ articles with a corresponding author was above $60 \%$ for the Nice, Caen, and Lille research areas. The distribution of top $10 \%$ cited articles by research field did not change markedly between the two time periods, but there were notable increases in the number of top $10 \%$ articles in neuroimaging, genetics, and epidemiology, three fields that received almost $30 \%$ of French Alzheimer Plan funding.

Figure 1a shows, for the 2009-2013 period, the relationship between AD scientific output in terms of volume (number of articles) and impact (proportion of top $10 \%$ globally cited articles, independent of author leadership), as well as the level of funding (size of the bubbles) in the major geographical research areas. Overall, there was a significant correlation $\left(R^{2}=0.70\right)$ between the level of financial support and the volume of scientific output (number of articles), but there was no correlation $\left(R^{2}=0.03\right)$ between the level of funding and the impact of scientific output (proportion of top $10 \%$ articles). The latter result reflects the observation that several geographical areas (e.g., Angers. Dijon, Rouen, Caen, and Nice) delivered a high proportion of top $10 \%$ cited articles despite relatively modest levels of funding.

Figure 1b shows the results of the analysis performed for CHUs using the SIGAPS author's affiliation. Overall, the mean contribution of CHUs involved in AD research was $48 \%$ of French publications. CHU involvement in $\mathrm{AD}$ research was variable within the geographical research areas. Five of the CHUs contributed to more than $50 \%$ of the SIGAPS-indexed publications: hospitals in partnership with the University Paris 06, as well as the CHUs from Toulouse, Bordeaux, Lille, and Montpellier.

Table 1 Change in the number and proportion of articles in leadership of French research areas between periods 2004-2008 and 2009-2013

\begin{tabular}{|c|c|c|c|c|c|c|c|}
\hline \multirow[b]{2}{*}{ Research areas } & \multicolumn{3}{|c|}{ 2004-2008 top $10 \%$ publications } & \multicolumn{3}{|c|}{ 2009-2013 top $10 \%$ publications } & \multirow{2}{*}{$\begin{array}{l}\text { Share of funding }(\% \\
\text { 2009-2013 }\end{array}$} \\
\hline & Leadership, n & Global top $10 \%, \mathrm{n}$ & Leadership, \% & Leadership, n & Global top $10 \%, \mathrm{n}$ & Leadership, \% & \\
\hline Nice & 2 & 6 & 33.3 & 17 & 25 & 68.0 & 5.2 \\
\hline Caen & 13 & 16 & 81.3 & 20 & 30 & 66.7 & 2.1 \\
\hline Lille & 10 & 15 & 66.7 & 36 & 56 & 64.3 & 10.6 \\
\hline Toulouse & 16 & 21 & 76.2 & 46 & 80 & 57.5 & 6.4 \\
\hline Paris 07 & 9 & 13 & 69.2 & 12 & 21 & 57.1 & 4.5 \\
\hline Rouen & 2 & 6 & 33.3 & 13 & 24 & 54.2 & 3.1 \\
\hline Paris 05 & 6 & 8 & 75.0 & 13 & 26 & 50.0 & 6.9 \\
\hline Angers & 0 & 2 & 0.0 & 11 & 22 & 50.0 & 1.5 \\
\hline Bordeaux & 15 & 24 & 62.5 & 23 & 51 & 45.1 & 10.5 \\
\hline Paris 06 & 23 & 34 & 67.6 & 28 & 63 & 44.4 & 14.1 \\
\hline Paris 11 & 7 & 17 & 41.2 & 18 & 46 & 39.1 & 3.5 \\
\hline Lyon & 5 & 11 & 45.5 & 12 & 33 & 36.4 & 3.6 \\
\hline Montpellier & 9 & 13 & 69.2 & 16 & 53 & 30.2 & 4.5 \\
\hline
\end{tabular}




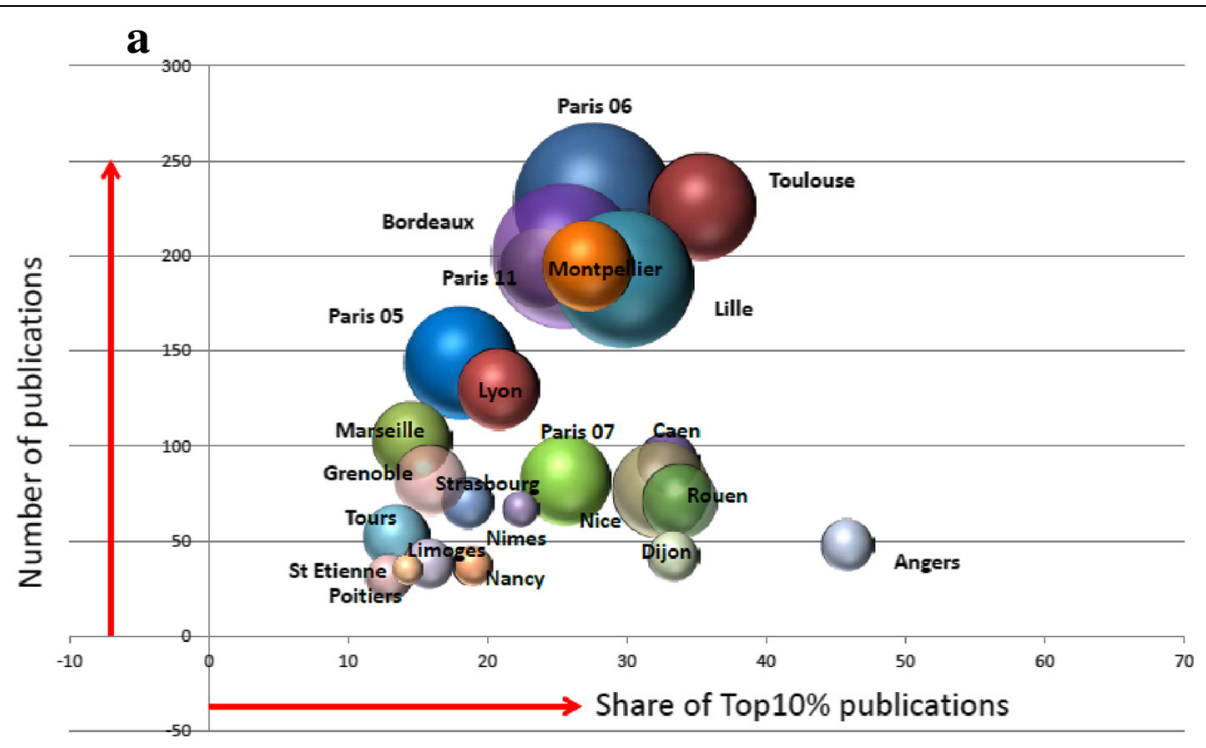

b

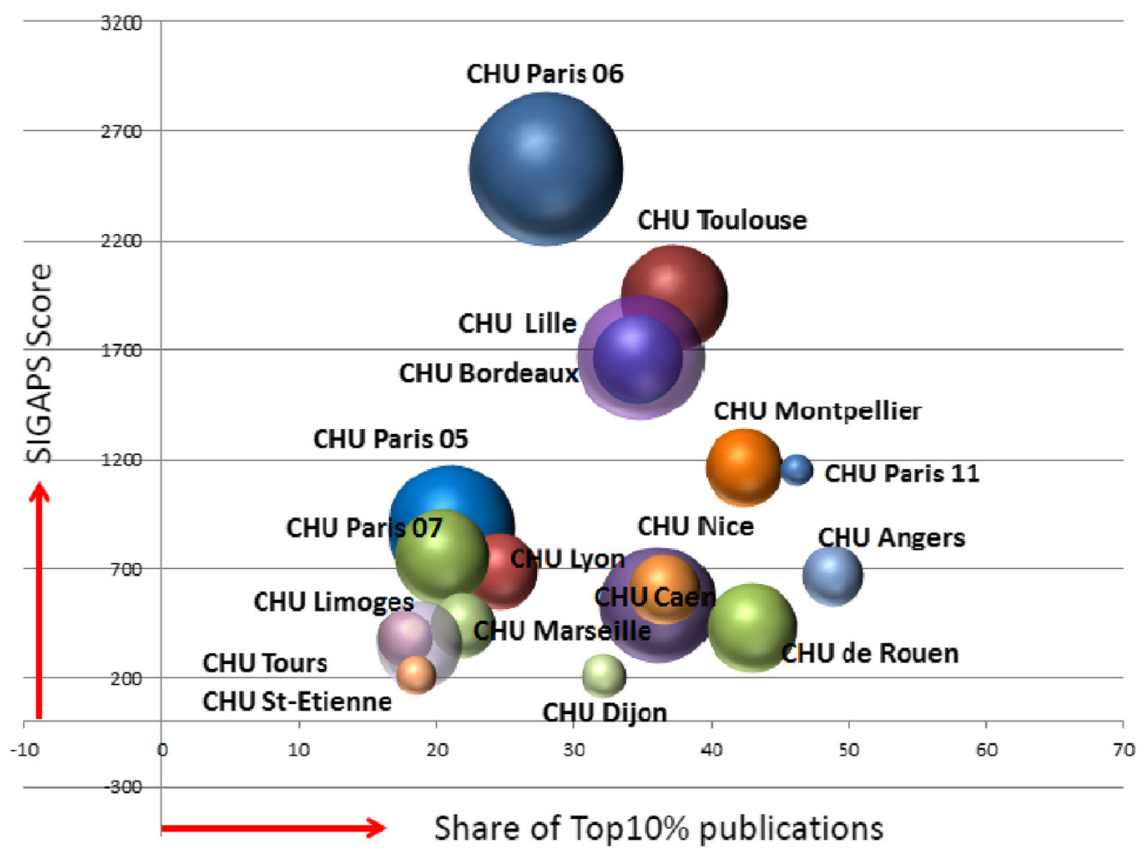

Fig. 1 Relationship between level of funding received from the Third French Alzheimer Plan, the volume (number of articles/SIGAPS score), and impact (representation in top $10 \%$ globally cited articles) of Alzheimer disease research in French geographical research areas and university hospitals (CHUs) in 2009-2013. a Relationship for each geographical research area of the total number of Alzheimer disease articles, the number of articles in the top $10 \%$ globally cited, and the relative level of funding received from the Third French Alzheimer Plan (size of bubble). b Relationship for each CHU of the SIGAPS score for Alzheimer disease articles (a measure of research output that takes into account factors including journal impact factor and the position of the authors within the author list), the number of articles in the top $10 \%$ globally cited, and the relative level of funding received from the Third French Alzheimer Plan (size of bubble)

As with the Web of Science analysis, we observed a high correlation $\left(R^{2}=0.96\right)$ between the SIGAPS score and the volume of scientific output (number of articles) for CHUs, but there was no correlation $\left(R^{2}=0.19\right)$ between the SIGAPS score and the proportion of top $10 \%$ articles.
Volume of French scientific research output in Alzheimer disease

To evaluate if the increase of scientific research output in $\mathrm{AD}$ in France was specific and not due to a global increase in research activity, we compared the change in scientific output between the periods 2004-2008 and 
2009-2013 in the most productive countries and compared output in AD with that in stroke, Parkinson disease, HIV, and diabetes.

Figure 2a shows that global scientific output across all research fields in the Web of Science database increased in all countries, with an overall $39 \%$ increase between the periods 2004-2008 and 2009-2013 (Table 2). The United States was by far the largest contributor of scientific articles in both periods, but its relative global contribution fell from $30 \%$ to $27 \%$ of total articles, reflecting the dramatic rise in the number of articles produced in countries such as China, India, South Korea, and Australia. France increased its output by 32 \% between the two time periods, but its global share decreased from $5.3 \%$ to $5.0 \%$. The global share for the United States, the United Kingdom, and other European countries declined as well. For AD, global scientific output increased by $46 \%$ between the periods 2004-2008 and 2009-2013, which was greater than the increase for Parkinson disease (40\%) and HIV (32\%) but lower than the output observed for stroke (55\%) and diabetes (49 \%). The absolute increase in scientific output for $\mathrm{AD}$ was higher than the global mean for China, India, Brazil, South Korea, Australia, Spain, and France.

Figure $2 \mathrm{~b}$ shows the relative change in scientific output between the periods 2004-2008 and 2009-2013 in each disease area in the top 14 countries, correcting for the overall change in output within each country. The relative change thus measures the extent to which $\mathrm{AD}$ research has increased compared with research in other disease areas within each country. France had the third largest relative increase in scientific output in $A D$ between the periods 2004-2008 and 2009-2013 (1.7 times higher than the overall increase in scientific output across all disease areas), behind only India (2.5) and China (1.9). In both France and Spain, the relative increase in scientific output in AD was larger than any of the other four major comparator disease areas.

\begin{tabular}{|c|c|c|c|c|c|c|}
\hline \multirow{2}{*}{ Country } & \multicolumn{6}{|c|}{ Output Increase (\%) between 2004-2008 and 2009-2013 } \\
\hline & All fields & Alzhemer & Stroke & Parkmson & HIV & Diabetes \\
\hline USA & 26.2 & [1 28.8 & $\begin{array}{l}43.7 \\
\end{array}$ & 27.5 & 28.4 & 35.3 \\
\hline CHINA & 109.8 & 207.1 & 239.0 & 190.5 & 118.2 & 252.2 \\
\hline UK & 31.3 & (1) 38.1 & प 44.7 & 25.3 & 33.8 & 33.2 \\
\hline GERMANY & 33.9 & 45.1 & $\square 49.2$ & 30.7 & 18.5 & 34.4 \\
\hline JAPAN & 10.1 & \ 13.5 & $\square 6.4$ & 8.6 & 9.8 & ] 26.0 \\
\hline FRANCE & 31.9 & $\square 54.6$ & $\square 2.5$ & 28.5 & 6.7 & 28.9 \\
\hline CANADA & 36.1 & (7) 38.1 & $\square 55.1$ & ] 36.5 & 53.5 & $\square 51.5$ \\
\hline ITALY & 41.4 & 口 38.8 & 104.0 & $\square 42.7$ & 7.4 & $\square 41.8$ \\
\hline SPAIN & 58.7 & $\square 75.8$ & $\square 64.2$ & $\square 50.1$ & 】 22.6 & $\square 54.0$ \\
\hline INDIA & 62.7 & 159.8 & 141.7 & 158.0 & 76.7 & 130.6 \\
\hline AUSTRALIA & 61.9 & 83.9 & $\$ 87.6$ & 56.1 & 59.4 & 69.7 \\
\hline SOUTH KOREA & 79.6 & 86.5 & 145.3 & 120.8 & 51.0 & 133.1 \\
\hline NETHERLANDS & 46.4 & 43.5 & 68.3 & 53.3 & 51.4 & 53.7 \\
\hline BRAZIL & 80.0 & 99.7 & 119.3 & 91.9 & 59.1 & 115.3 \\
\hline World & 39.2 & 46.2 & 55.2 & 39.7 & 31.6 & 48.7 \\
\hline
\end{tabular}

b

\begin{tabular}{|c|c|c|c|c|c|c|}
\hline \multirow{2}{*}{$\begin{array}{c}\text { World Share (\%) } \\
2004-2013 \\
\end{array}$} & \multirow[b]{2}{*}{\begin{tabular}{|l|} 
Countries \\
\end{tabular}} & \multicolumn{5}{|c|}{ Rehative to Country Increase between 2004-2008 and 2009-2013 } \\
\hline & & Atzheimer & Stroke & Parkinson & HIV & Diabetes \\
\hline 28.2 & USA & $\square \quad 1.1$ & 1.7 & 1.0 & 1.1 & \begin{tabular}{|l|l|} 
& 1.3 \\
\end{tabular} \\
\hline 11.4 & PEOPLES R CHINA & 19 & 2.2 & $\square 1.7$ & $\square 1.1$ & $2 / 3$ \\
\hline 7.6 & UK & $\square 1.2$ & 1.4 & $\square 0.8$ & $\square 1.1$ & $\square 1.1$ \\
\hline 7.3 & GERMANY & 1.3 & 1.4 & $\square 0.9$ & 0.5 & $\square 1.0$ \\
\hline 6.5 & JAPAN & 1.3 & 4.6 & $\square 0.9$ & 1.0 & 2.6 \\
\hline 5.1 & FRANCE & 1.7 & 1.6 & $\square \quad 0.9$ & 0.2 & $\square \quad 0.9$ \\
\hline 4.5 & CANADA & $\square \quad 1.1$ & 1.5 & $\square \quad 1.0$ & 1.5 & $\square 1.4$ \\
\hline 4.1 & ITALY & $\square 0.9$ & 2.5 & $\square 1.0$ & 0.2 & $\square \quad 1.0$ \\
\hline 3.6 & SPAIN & $\square 1.3$ & $\square 1.1$ & $\square 0.9$ & 0.4 & $\square \quad 0.9$ \\
\hline 3.4 & INDIA & 2.5 & $2 / 3$ & 2.5 & 1.2 & 2.1 \\
\hline 3.2 & AUSTRALIA & $\square 1.4$ & 1.4 & $\square 0.9$ & $\square 1.0$ & $\square \quad 1.1$ \\
\hline 3.2 & SOUTH KOREA & $\square 1.1$ & 1.8 & $\square 1.5$ & 0.6 & $\square 1.7$ \\
\hline 2.5 & NETHERLANDS & $\square \quad 0.9$ & $\square 1.5$ & $\square \quad 1.1$ & $\square 1.1$ & $\square \quad 1.2$ \\
\hline 8.3 & BRAZIL & $\square 1.2$ & 1.5 & $\square 1.1$ & $\square \quad 0.7$ & 1.4 \\
\hline 100 & World & 1.2 & 1.4 & 1.0 & 0.8 & 1.2 \\
\hline
\end{tabular}

Fig. 2 Increase in country publication output between the periods 2004-2008 and 2009-2013 for five major disease areas (Alzheimer disease, stroke, Parkinson disease, HIV, and diabetes) in absolute terms and relative to the overall output within each country. a Percentage increase in the number of publications overall and in each disease area between the periods 2004-2008 and 2009-2013. The top 14 countries worldwide are ranked according to their contribution during the period 2004-2008. b For each country, the fold increase in the proportion of publications in each disease area relative to the overall increase in the number of publications between the periods 2004-2008 and 2009-2013 is shown. The top 14 countries worldwide are ranked according to their contribution during the period 2004-2008 
Table 2 Number of published articles for the top 14 countries worldwide during the time periods 2004-2008, 2009-2013 and 2004-2013, across all disease areas and specifically in Alzheimer disease and the four major comparator disease states (stroke, Parkinson disease, HIV and diabetes)

\begin{tabular}{|c|c|c|c|c|c|c|c|c|c|c|c|c|c|}
\hline & \multicolumn{3}{|l|}{ All } & \multicolumn{2}{|l|}{ Alzheimer } & \multicolumn{2}{|l|}{ Stroke } & \multicolumn{2}{|l|}{ Parkinson } & \multicolumn{2}{|l|}{ HIV } & \multicolumn{2}{|l|}{ Diabetes } \\
\hline & 2004-2013 & 2004-2008 & 2009-2013 & 2004-2008 & 2009-2013 & 2004-2008 & $2009-2013$ & 2004-2008 & $2009-2013$ & 2004-2008 & 2009-2013 & 2004-2008 & 2009-2013 \\
\hline United States & $2,949,083$ & $1,303,555$ & $1,645,528$ & 11,260 & 14,499 & 11,561 & 16,615 & 6537 & 8335 & 20,976 & 26,938 & 25,006 & 33,842 \\
\hline China & $1,188,127$ & 383,509 & 804,618 & 1247 & 3830 & 1289 & 4370 & 665 & 1932 & 1577 & 3441 & 2413 & 8499 \\
\hline United Kingdom & 795,735 & 343,455 & 451,080 & 2487 & 3435 & 3241 & 4689 & 1767 & 2214 & 4080 & 5461 & 5822 & 7752 \\
\hline Germany & 757,711 & 323,922 & 433,789 & 2037 & 2956 & 2950 & 4400 & 1772 & 2316 & 1928 & 2285 & 4516 & 6069 \\
\hline Japan & 675,315 & 321,389 & 353,926 & 2240 & 2543 & 2328 & 3408 & 1451 & 1576 & 1369 & 1503 & 5706 & 7192 \\
\hline France & 537,568 & 231,875 & 305,893 & 1250 & 1932 & 1485 & 2264 & 997 & 1281 & 3123 & 3331 & 2890 & 3726 \\
\hline Canada & 467,998 & 198,202 & 269,796 & 1448 & 1999 & 1974 & 3061 & 992 & 1354 & 1963 & 3014 & 3227 & 4889 \\
\hline Italy & 424,650 & 175,930 & 248,720 & 1775 & 2463 & 1358 & 2770 & 1232 & 1758 & 2090 & 2244 & 3681 & 5219 \\
\hline Spain & 375,748 & 145,233 & 230,515 & 1010 & 1776 & 1029 & 1690 & 817 & 1226 & 1811 & 2221 & 2185 & 3364 \\
\hline India & 353,056 & 134,381 & 218,675 & 296 & 769 & 319 & 771 & 207 & 534 & 1201 & 2122 & 1512 & 3487 \\
\hline Australia & 334,610 & 127,767 & 206,843 & 822 & 1512 & 1172 & 2199 & 510 & 796 & 1298 & 2069 & 2442 & 4144 \\
\hline South Korea & 329,696 & 117,933 & 211,763 & 743 & 1386 & 892 & 2188 & 432 & 954 & 337 & 509 & 1588 & 3702 \\
\hline Netherlands & 257,829 & 104,649 & 153,180 & 830 & 1191 & 1207 & 2031 & 531 & 814 & 1106 & 1675 & 2137 & 3285 \\
\hline Brazil & 861,367 & 93,334 & 168,033 & 377 & 753 & 450 & 987 & 270 & 518 & 1273 & 2025 & 1384 & 2980 \\
\hline World & $10,439,490$ & $4,364,842$ & $6,074,648$ & 26,190 & 38,302 & 32,552 & 50,506 & 17,219 & 24,059 & 42,679 & 56,171 & 68,575 & 101,968 \\
\hline
\end{tabular}




\section{Impact of French scientific research output in Alzheimer disease}

Table 3 shows the relative change in the level (number of articles) and impact (proportion of articles in top $1 \%$ globally cited) of French scientific research output in AD relative to the four major comparator disease areas between the periods 2004-2008 and 2009-2013. These results indicate that French scientific output in $\mathrm{AD}$ increased 3.9-fold more than the overall level of French scientific output between the periods 2004-2008 and 2009-2013, reflecting faster growth in AD research output than was observed for stroke, Parkinson disease, HIV, and diabetes. This quantitative rise also appeared to be reflected in an increase in the relative impact of articles in AD. There was a 2.3-fold increase between the periods 2004-2008 and 20092013 in the proportion of French AD articles in the top $1 \%$ globally cited, which was also a greater rise than that observed for all of the four major comparator disease areas.

Table 4 shows the output of $\mathrm{AD}$ articles, the relative citation impact, and the number and proportion of articles represented in the top $1 \%$ cited globally for the six EU countries that contributed the most between 2004 and 2013. Whereas the United Kingdom and Germany contributed the greatest number of $\mathrm{AD}$ articles during both 2004-2008 and 2009-2013, the relative citation impact rose for all six countries, with an increase from 1.3 to 1.9 for France. Similarly, the proportion of top $1 \%$ articles increased for all countries, including France (from $1.7 \%$ to $2.4 \%$ ). Further analysis of the top $1 \%$ articles showed that the predominant field of research in AD varied among countries. The proportion of articles on clinical investigation was $>30 \%$ in the United Kingdom, the Netherlands, Spain, and Italy and approximately $20 \%$ in France and Germany. Compared with the other EU countries, French articles in AD showed a greater representation of research in epidemiology, genetics, and imaging.

\section{Discussion}

Our results show an overall acceleration following the Third French Alzheimer Plan of the academic scientific output of France in AD research in terms of both volume and impact. Bibliometric analysis enabled assessment of the scientific impact of the plan on different geographical areas within France. The results show that six research areas contributed to almost $50 \%$ of French $\mathrm{AD}$ articles. A positive correlation was observed between the level of financial support and global scientific contribution of the different geographical areas, although no correlation was detected between level of funding and article quality and/or impact. The increase in French AD research output was higher than for the four comparator disease areas and was the highest among other major European countries. Taken together, our bibliometric results show a specific impact of the Third French Alzheimer Plan.

Although the results of bibliometric approaches must be interpreted with caution and due consideration, given their limitations [4-6], the main points for discussion from our study are not a bibliometric ranking of research between different countries or different French geographical research areas per se, but the answer to two major questions: (1) Did the funding of a national Alzheimer plan expand academic research on $\mathrm{AD}$ and related dementias (if yes, where and by how much)? (2) What conclusions can be drawn for future consideration when this evidence is made public to encourage and increase the productivity of academic research (in which specific fields and by which collaborations)?

Despite the context of a global proliferation of scientific publications, which reflects as much an increase in production as it does many changes in editorial policies and pressures to publish, our study leaves no doubt that the French research contribution to AD increased considerably between the periods 2004-2008 and 20092013 in terms of both volume (number of articles) and impact (assessed by the relative representation of articles

Table 3 Change in the impact of French Alzheimer disease research between the periods 2004-2008 and 2009-2013, as assessed by research output and representation in the top $1 \%$ globally cited articles compared with French scientific output in stroke, Parkinson disease, HIV, and diabetes

\begin{tabular}{|c|c|c|c|c|c|c|}
\hline & \multicolumn{2}{|c|}{$\begin{array}{l}\text { Research output } \\
\text { (\% France's share of output) }\end{array}$} & \multirow[t]{2}{*}{$\begin{array}{l}\text { Output relative increase } \\
\text { (fold change) }\end{array}$} & \multicolumn{2}{|c|}{$\begin{array}{l}\text { France's share of top } 1 \% \text { globally } \\
\text { cited articles }\end{array}$} & \multirow[t]{2}{*}{$\begin{array}{l}\text { Top } 1 \% \text { relative increase } \\
\text { (fold change) }\end{array}$} \\
\hline & 2004-2008 & 2009-2013 & & 2004-2008 & 2009-2013 & \\
\hline Alzheimer disease & $1,082(0.4 \%)$ & $1,836(0.6 \%)$ & 3.9 & $18(0.7 \%)$ & $44(1.1 \%)$ & 2.3 \\
\hline Diabetes & $2,890(1.1 \%)$ & $3,725(1.2 \%)$ & 1.6 & $75(3.0 \%)$ & $130(3.2 \%)$ & 1.2 \\
\hline HIV & 3, $092(1.1 \%)$ & $3,297(1.0 \%)$ & 0.4 & $43(1.7 \%)$ & $58(1.4 \%)$ & 0.6 \\
\hline Parkinson disease & 997 (0.4 \%) & 1, $281(0.4 \%)$ & 1.6 & $17(0.7 \%)$ & $21(0.5 \%)$ & 0.4 \\
\hline Stroke & 1, $495(0.5 \%)$ & 2, $264(0.7 \%)$ & 2.9 & $46(1.8 \%)$ & $98(2.0 \%)$ & 1.8 \\
\hline Overall & 270,314 & 318,946 & 1 & 2,496 & 4,041 & 1 \\
\hline
\end{tabular}


Table 4 Relative impact of French Alzheimer disease research between the periods 2004-2008 and 2009-2013, as assessed by research output and representation in the top $1 \%$ globally cited articles for France and the other top 5 leading EU countries

\begin{tabular}{|c|c|c|c|c|c|c|c|c|}
\hline \multirow[b]{2}{*}{ Country } & \multicolumn{4}{|l|}{ 2004-2008 } & \multicolumn{4}{|l|}{ 2009-2013 } \\
\hline & $\begin{array}{l}\text { Output of } \\
\text { articles }\end{array}$ & $\begin{array}{l}\text { Relative citation } \\
\text { impact }\end{array}$ & $\begin{array}{l}\text { Number in top } \\
1 \% \text { globally } \\
\text { cited articles }\end{array}$ & $\begin{array}{l}\text { Percent in top } \\
1 \% \text { globally } \\
\text { cited articles }\end{array}$ & $\begin{array}{l}\text { Output of } \\
\text { articles }\end{array}$ & $\begin{array}{l}\text { Relative } \\
\text { citation } \\
\text { impact }\end{array}$ & $\begin{array}{l}\text { Number in top } \\
1 \% \text { globally } \\
\text { cited articles }\end{array}$ & $\begin{array}{l}\text { Percent in top } \\
1 \% \text { globally } \\
\text { cited articles }\end{array}$ \\
\hline France & 1082 & 1.34 & 18 & 1.66 & 1836 & 1.92 & 44 & 2.40 \\
\hline Germany & 1596 & 1.56 & 25 & 1.57 & 2316 & 2.16 & 65 & 2.81 \\
\hline Italy & 1274 & 1.38 & 13 & 1.02 & 1797 & 1.67 & 30 & 1.67 \\
\hline Netherlands & 720 & 1.78 & 17 & 2.36 & 1087 & 2.72 & 28 & 2.58 \\
\hline Spain & 1001 & 1.02 & 4 & 0.40 & 1884 & 1.76 & 22 & 1.17 \\
\hline United Kingdom & 1681 & 1.66 & 43 & 2.56 & 2294 & 2.59 & 81 & 3.53 \\
\hline
\end{tabular}

in the top $1 \%$ globally cited). French scientific output in $\mathrm{AD}$ increased more in quantity and quality by comparison to several major countries and, within the country itself, by comparison with research productivity in other fields, such as Parkinson disease, HIV, and diabetes. It is noteworthy that with stroke, a field supported by a specific plan (2010-2014) [7], the difference is less marked. Our study showed that, at the national level, the CHUs are major players in French research, participating in $48 \%$ of French AD publications. Almost all CHUs increased their output after the Third French Alzheimer Plan, improving both their SIGAPS score (based on journal impact factor and author position) and their proportion of top $10 \%$ globally cited publications (with or without leadership position). Analyses by geographical area demonstrated notable heterogeneity at a regional level, with the majority of the scientific output coming from six areas. Whereas some of these contained centers that are well established in $\mathrm{AD}$ research, two small, focused research areas emerged as a result of the plan. We compared the percentage of top $10 \%$ cited publications, rather than the number of top $10 \%$ publications (which is related to the number of researchers), as a measure of impact. Whereas during the 2004-2008 period only four research areas had more than $20 \%$ of their articles in the top $10 \%$ most cited (Caen, Paris 06, Paris 07, and Bordeaux), after the plan 16 research areas reached that level and 4 were above $30 \%$ (Angers, Toulouse, Rouen, and Dijon). It is noteworthy that all fields of biomedical research are not equally developed in all geographical research areas, and public knowledge about the diversity of the strongest points of each site may encourage collaborations in large-scale projects at a national level.

Our juxtaposition of the level of funding and production of original articles should be interpreted with caution. First, a public health plan is more than a financing issue. Through governmental support, such a plan should generate a nationwide mobilization to engage a range of stakeholders across scientific, medical, and social networks (e.g., the National Center for Ethics, France Alzheimer, and the Médéric Alzheimer Foundation). Fifty universities offered young researchers, pharmacists, and physicians 2-year hospital positions and a 1-year training grant on drug development, which led to recruitment of a total of 72 health professionals. The Third French Alzheimer Plan also mobilized broader activities across the EU at the time of French presidency in 2008. A bibliometric analysis focusing on scientific literature cannot measure the wider societal impact of such an investment, in France and in the EU in terms of raising awareness of AD. Second, there is a significant lag time between funding allocation and the publication of scientific articles. Although our review considered a 5-year time period after initiation of the plan, this may not be sufficient for areas such as clinical research, where there are significant administrative and ethical issues to be addressed in implementing new projects. Indeed, the choice was made in France not to create a new institute or agency similar to what was done for cancer and HIV research. Instead, with a very small administrative structure, the Third French Alzheimer Plan rapidly delivered support for previously productive areas of research (e.g., epidemiology and genetics) within 2 years. More comprehensive infrastructure projects, such as the Memento Cohort and the Acquisition Center and Image Processing, were then initiated, but they will deliver results over a longer time frame than 5 years.

With these caveats in mind, analysis of the correlation between level of funding and scientific output across French geographical research areas yielded some interesting results. Whereas there was a strong correlation between funding and the volume of scientific output, no such correlation was observed between funding and article impact (proportion of top $10 \%$ articles). It may therefore be more appropriate for future allocation of research funding to take into account bibliometric analyses such as ours that assess the impact of a group's research in addition to the volume of their output. Along similar lines for CHUs, the strong correlation observed between SIGAPS score and volume of scientific output was expected. The lack of correlation between SIGAPS score 
and the proportion of top $10 \%$ cited articles strengthens arguments that assessments of research groups must take into account both the impact factor of target journals and publication citations to draw appropriate conclusions on performance. There may be multiple reasons for the observed lack of correlation between funding and article impact; for example, some areas of research were of greater current interest and were therefore more likely to attract more citations during the period of evaluation (e.g., neuroimaging in the Caen area). Similarly, some research projects are more internationalized and may therefore attract more citations (e.g., clinical investigations in Toulouse). Some geographical research areas are likely to have benefited from other, international sources of funding to conduct high-impact research and could therefore have generated publications with a scientific output apparently uncorrelated with the level of funding from the Third French Alzheimer Plan.

At the global level, the United States is the leading country for scientific research. It produced almost 26,000 articles in AD (approximately $40 \%$ of global output in the field) during the period 2004-2013. The majority of funding for $\mathrm{AD}$ research in the United States comes from the federal government via the National Institute on Aging (NIA), and, since 1985, AD Centers and AD research Centers have been established in major medical schools. In France, by contrast, university memory centers for research and appeal were only established in 2002, and only during the Third French Alzheimer Plan were these extended nationwide. Despite the 2008 financial crisis, major investments in Alzheimer research were announced by several countries in Europe (notably the United Kingdom and Germany) and, later on, by the United States. According to our analysis, the United Kingdom and Germany remain major contributors in AD, ahead of France. Several other countries also contributed in quantity and quality to worldwide academic output, in some cases (Australia, the Netherlands, and Germany) as a result of national AD/dementia plans. There are as yet no national dementia plans in other countries, such as China, India, and South Korea [8-11], but these countries face a major demographic challenge in terms of the age profile of their populations, and it is notable that they have dramatically accelerated their research in $\mathrm{AD}$ and other disease areas. Following this first attempt to identify an association between a national investment in research on a disease and the level of scientific output, it would now be useful to investigate in these other countries (1) the final grant attributions by comparison with the initial political announcements and (2) the evolution in each country's global scientific output. An international working group on this issue would be helpful to improve and standardize methodology for the selected indices and address the delays of follow-up between grant attribution and publication of original articles.

\section{Conclusions}

Our study provides evidence of the probable impact of a national effort in France to stimulate improved diagnosis and treatment of $\mathrm{AD}$ and dementia, which focused on original research as far as possible in the economic context. We believe that bibliometric assessment and analysis, whatever its limits, should be mandatory at a time when many countries have launched specific initiatives to promote research in $\mathrm{AD}$ and dementia (exemplified by the recent Global Action Against Dementia summit). Given that a minimum 5-year interval is essential to ensuring a sufficient production of original articles and to measure their impact, we advocate a continuous process for bibliometric assessment rather than a one-time, snapshot approach. Such an approach would contribute to better orientation of scientific policies within and between countries and encourage national and international collaborations around the most productive sites in certain fields of research, rather than using bibliometric analysis primarily as a tool to benchmark universities or countries.

\section{Additional file}

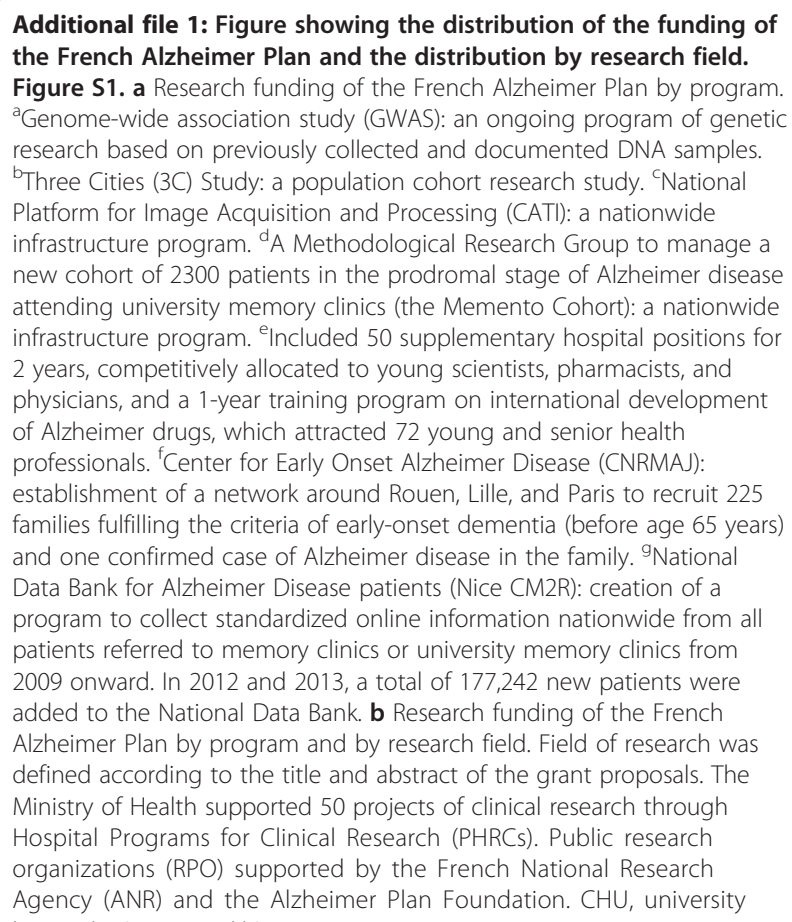

\section{Abbreviations}

AD: Alzheimer disease and related disorders; ANR: National Agency for Research; CADASIL: cerebral autosomal dominant arteriopathy with subcortical infarcts and leukoencephalopathy; $\mathrm{CHU}$ : university hospital; ESI: Thomson Reuters Essential Science Indicators; EU: European Union; PHRC: Hospital Program for Clinical Research; RPO: Public Research Organization. 


\section{Competing interests}

$\mathrm{NHC}, \mathrm{PD}$ and SL declare that they have no competing interests. JM reports receiving personal fees from Actelion, Sanofi, and Novartis that are not relevant to the submitted work. JM was chair and overall leader of the Third French Alzheimer Plan but reports no potential financial or professional competing interests regarding the analysis of the impact of the plan.

\section{Authors' contributions}

All authors contributed to the overall study design and study conduct. $\mathrm{NHC}$ is the guarantor for the study and produced, analyzed, and interpreted data from the Web of Science. PD produced, analyzed, and interpreted data from the SIGAPS System. SL provided, analyzed, and interpreted financial data from the French Alzheimer Plan. Given his position as Chair and overall leader of the Third French Alzheimer Plan, JM committed a priori to publication of the study data, regardless of the findings, and played no role in the production, extraction, or analysis of data from original sources. JM worked with $\mathrm{NHC}, \mathrm{PD}$, and $\mathrm{SL}$ in the interpretation of the data. JM and $\mathrm{NHC}$ wrote the first draft of the manuscript and made revisions according to recommendations of PD and SL. All authors had full access to all of the data in the study (with the caveat above that JM was not involved in the production, extraction, or analysis of data) and take responsibility for the integrity of the data and the accuracy of the data analysis. NHC affirms that the article is an honest, accurate, and transparent account of the study being reported, that no important aspects of the study have been omitted, and that there were no discrepancies from the study as planned. All authors read and approved the final manuscript.

\section{Acknowledgments}

The authors acknowledge the support of Dr Richard White (Oxford PharmaGenesis), a professional medical writer, in editing and formatting the final manuscript draft for journal submission.

\section{Funding}

This support was funded by INSERM, the Fondation Plan Alzheimer, and the Association Robert Debré pour la Recherche Médicale.

\section{Author details}

'INSERM, Department of Scientific Evaluation, Bibliometric Unit, 101 Rue Tolbiac, F-75014 Paris, France. ${ }^{2}$ Department of Research, University of Lille, CHU Lille, EA2694, F-59000 Lille, France. ${ }^{3}$ Fondation Plan Alzheimer, F-75013 Paris, France. ${ }^{4}$ Faculté de médecine Paris-Descartes, 15 rue de l'Ecole de Médecine, Paris, France. ${ }^{5}$ Centre d'Investigations Cliniques 1418, F-75006 Paris, France.

Received: 18 May 2015 Accepted: 7 August 2015

Published online: 26 September 2015

\section{References}

1. Spinney L. Alzheimer's disease funding and the French health system. Lancet Neurol. 2008;7:26-7.

2. Leydesdorff L. Alternatives to the journal impact factor: 13 and the top-10\% (or top-25\%?) of the most-highly cited papers. Scientometrics. 2012:92:355-65.

3. Rouvillain $J$, Derancourt C, Moore N, Devos P. Scoring of medical publications with SIGAPS software: application to orthopedics. Orthop Traumatol Surg Res. 2014;100:821-5.

4. van Raan T. Bibliometrics: measure for measure. Nature. 2010;468:763.

5. Sahel JA. Quality versus quantity: assessing individual research performance. Sci Transl Med. 2011:3:84cm13.

6. Bornmann L, Leydesdorff $L$. The validation of (advanced) bibliometric indicators through peer assessments: a comparative study using data from InCites and F1000. J Informetr. 2013;7:286-91.

7. Lebrun L, Rusterholtz T, Fery-Lemonnier E, Woimant F, Leroyer J, Hommel M. Improving stroke care: a French health-care organiser's perspective. Int J Stroke. 2011;6:123-4

8. Alzheimer Europe. France - national plans for Alzheimer and related diseases. http://www.alzheimer-europe.org/Policy-in-Practice2/NationalDementia-Plans/France. Accessed 4 September 2015.

9. Alzheimer Europe. United Kingdon (England) - national dementia plans. http://www.alzheimer-europe.org/Policy-in-Practice2/National-DementiaPlans/United-Kingdom-England\#fragment-1. Accessed 4 September 2015.
10. Alzheimer Europe. Dutch dementia care plan - national dementia plans. http://www.alzheimer-europe.org/Policy-in-Practice2/National-DementiaPlans/Netherlands\#fragment-1. Accessed 4 September 2015.

11. Alzheimer Europe. Spain - national dementia plans. http://www.alzheimereurope.org/Policy-in-Practice2/National-Dementia-Plans/Spain. Accessed 4 September 2015

\section{Submit your next manuscript to BioMed Central and take full advantage of:}

- Convenient online submission

- Thorough peer review

- No space constraints or color figure charges

- Immediate publication on acceptance

- Inclusion in PubMed, CAS, Scopus and Google Scholar

- Research which is freely available for redistribution

Submit your manuscript at www.biomedcentral.com/submit 